\title{
Analysis of Land Use in Jining City
}

\author{
Nanjia Lu${ }^{1}$, Xingyuan Xiao ${ }^{1 *}$ \\ ${ }^{1}$ College of geomatics, Shandong University of Science and Technology, Qingdao, Shandong, 266590, China
}

\begin{abstract}
Jining City is a typical area with complex and diverse landforms, developed water systems and rich mineral resources. Research on its land use changes will be of great significance in terms of sustainable development and ecological protection. This paper is based on the four LANDSAT remote sensing image data in 2000, 2005, 2010 and 2015, using RS, GIS, mathematical statistics and other methods, mainly analyze the land use of Jining City from 2000 to 2015 from three aspects: land use structure, land use characteristics and problems, land use area and structure changes. The results show that: (1) Jining City has the largest area of dry land, which is widely distributed in various regions; followed by construction land, water, grass, woodland, paddy field, and unutilized land. (2) The land use characteristics of Jining City are: high arable land rate, high land utilization rate, large proportion of water area, abundant surface water resources, and obvious regional differences in land use; the problems are that the land use structure is unreasonable, per capita land resources are few, and the contradiction between people and land has become increasingly prominent. (3) On the whole, land use changes in Jining City are relatively complex. The town house area has been showing an increasing trend; the grass area has shown a continuous decreasing trend; the fluctuations of dry land, paddy field, woodland, house-site in the countryside, water, and unutilized land area fluctuations are obvious. During the 15 years from 2000 to 2015, the largest change in the land use structure of Jining City was town house, followed by paddy field, house-site in the countryside, dry land, grass, woodland, unutilized land, and water. The area of town house, dry land, forest land, and water has increased, while the area of paddy field, house-site in the countryside, grass, and unutilized land has decreased.
\end{abstract}

\section{Introduction}

Research on land use change has now become a classic topic worldwide, since the International Geosphere Biosphere Programme (IGBP) and International Human Dimension Programme on Global Environmental Change (IHDP) jointly published the Land Use/Cover Change Scientific Research Program in 1995, Many scholars have carried out research on the main content of land use change forms and types, process analysis and driving factors analysis. In traditional research, Skole believes that the completion of relevant research requires three levels of work: measuring spatio-temporal features, acquiring dynamic processes, predicting trends, and their effects[1]. With the development of satellite and computer technology, the extensive application of RS, GIS technology and its supporting software and model analysis has become an important tool for land use change. For example, Kienast summarizes the classic GIS spatial statistical methods and spatial overlay analysis[2], Iverson used GIS technology to analyze the land use change in Illinois[3], and Tang summarized various LUCC models[4]. In recent years, computer artificial intelligence and deep learning have made image processing and change analysis more efficient and faster.In recent years, Chinese land use change research work mainly includes: Li Xiubin, Li Mao and others study the impact of land use change on food security[56]; Shi Peijun, Li Jing and others study the impact of land use change on the ecological environment[7-8]; Liu Jiyuan and others study the national land use change Time and space patterns and new features[9-10].

Jining City is a typical area with rich mineral resources and developed water system, at the same time of rapid socio-economic development, various urbanization problems and ecological environment issues are becoming more and more prominent; studying the issue of land use change will better guide regional coordinated development and sustainable development, optimize land use structure, correctly handle conflicts between people and land, and build a harmonious society.

\section{Study area and data}

\subsection{Study area}

Jining City is located in the hinterland of southwest Shandong Province. The geological structure belongs to the depression area of southwestern Shandong. Its terrain is dominated by plain and depressions, the terrain is high in the east and low in the west, and the landform is more 
complicated. There are lots of mountains in the eastern region. The four endpoints are located at $35^{\circ} 57^{\prime} \mathrm{N}$, $34^{\circ} 26^{\prime} \mathrm{S}, 117^{\circ} 36^{\prime} \mathrm{E}, 15^{\circ} 52^{\prime} \mathrm{W}$. It is $167 \mathrm{~km}$ long from north to south and $158 \mathrm{~km}$ long from east to west. Rich in mineral resources, there are more than 70 kinds of minerals that have been discovered and proven reserves. The plain area of the city is mainly composed of agricultural land and construction land. Woodland and grass are concentrated in the mountainous hills in the east, and the southeast is the Nansi Lake, the largest lake in Shandong Province. Jining City has jurisdiction over 11 districts and counties (cities) including Rencheng District, Yanzhou District, Weishan County, Yutai
County, Jinxiang County, Jiaxiang County, Wenshang County, Sishui County, Liangshan County, Qufu City and Zoucheng City.

\subsection{Data sources and image processing}

Jining City has a large span from north to south. In order to dynamically monitor land use/cover change, LANDSAT remote sensing images (track numbers $122 / 35,122 / 36$ ) were selected for 2000, 2005, 2010 and 2015. The main remote sensing data is shown in Table 1.

Table 1. RS date table.

\begin{tabular}{ccccc}
\hline Date & 2000.09 .14 & 2005.04 .16 & 2010.08 .30 & 2015.10 .02 \\
\hline resolution & $30 \mathrm{~m}$ & $30 \mathrm{~m}$ & $30 \mathrm{~m}$ & $30 \mathrm{~m}$ \\
data sources & Landsat5 & Landsat5 & Landsat7 & Landsat8 \\
\hline
\end{tabular}

According to the actual situation of the study area and the quality of remote sensing images, the preprocessing of remote sensing images mainly includes image radiation correction, geometric correction, band combination, image mosaic-cutting and so on.

According to the Classification of Land Use Status jointly issued by the General Administration of Quality Supervision, Inspection and Quarantine and the State Administration of Standardization on September 3, 2007, a land use classification system was formulated.

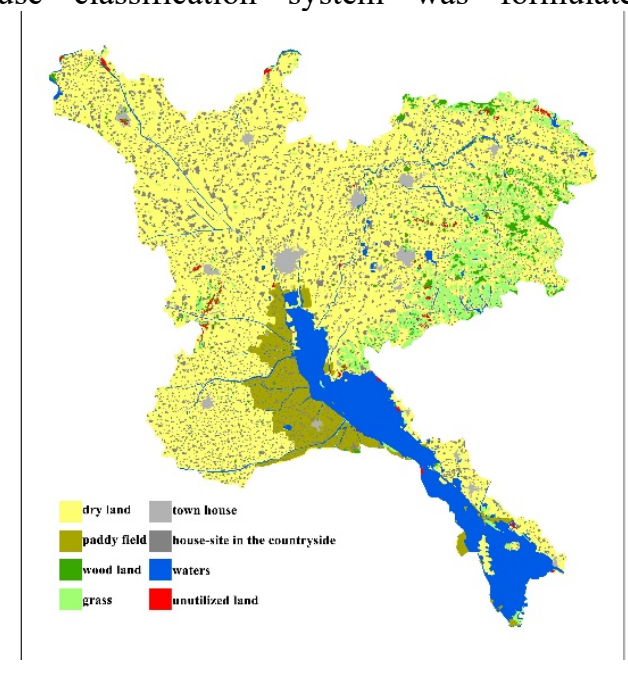

Figure1. Classification map of land use in Jining City in 2000.
According to the actual situation of the study area, the land use types are divided into dry land, paddy field, woodland, grass, town house, house-site in the countryside, waters and unutilized, and the land use types determined in accordance with Jining City remote sensing interpretation marks. This paper uses automatic interpretation and visual interpretation to extract land use information. Finally, the land use classification maps of Jining City in 2000, 2005, 2010 and 2015 are shown in Figure 1, 2, 3 and 4.

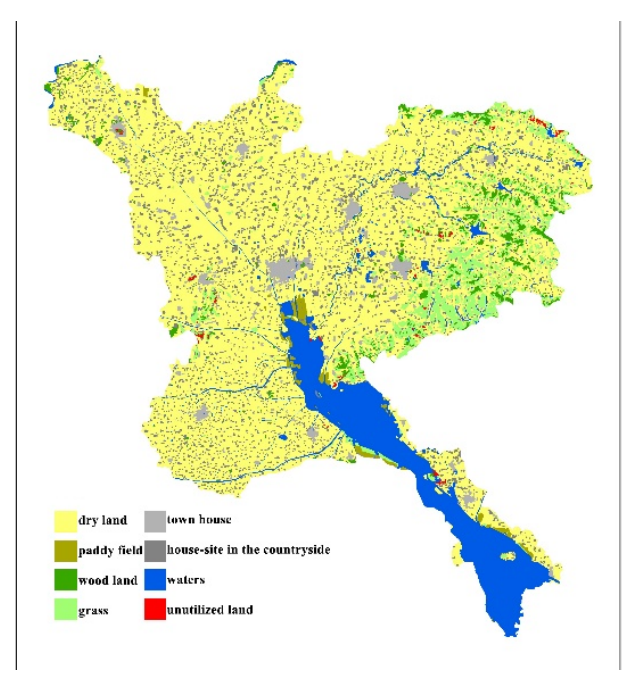

Figure2. Classification map of land use in Jining City in 2005. 


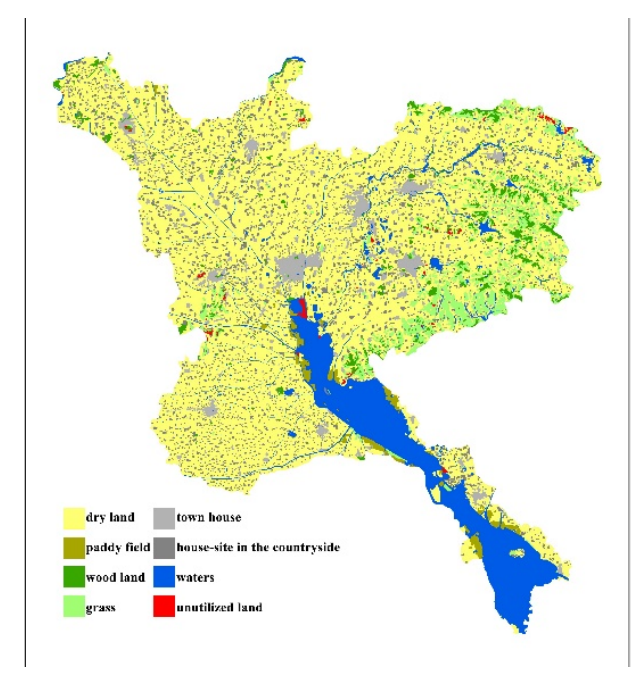

Figure3. Classification map of land use in Jining City in 2010.

\section{Analysis of land use status}

\subsection{Analysis of land use land use structure}

According to the analysis of the land use interpretation data of Jining City in 2015, the total land area of Jining City is $1108694.71 \mathrm{hm}^{2}$, accounting for $7.06 \%$ of the total area of the province. It can be seen from the Table 2 that Jining City has the largest area of dry land, about $651505.39 \mathrm{hm}^{2}$, accounting for $58.76 \%$ of the total area of Jining City. The second is construction land, accounting for $23.3 \%$ of the city's total area, of which house-site in the countryside accounts for $16.79 \%$, and town house accounts for $6.51 \%$. The waters is area $135459.84 \mathrm{hm}^{2}$, accounting for $12.22 \%$ of the city area.

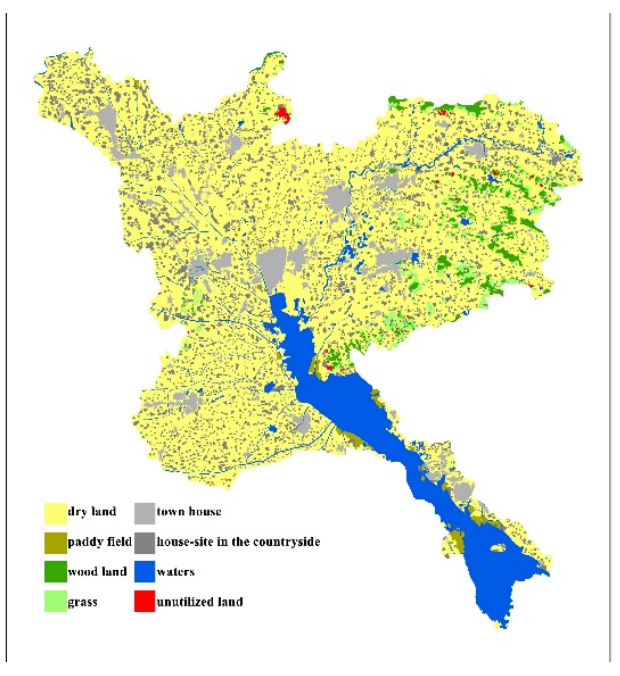

Figure4. Classification map of land use in Jining City in 2015.

Grass, woodland, paddy field, and unutilized land are relatively small, accounting for $2.37 \%, 2.26 \%, 0.83 \%$ and $0.26 \%$ of the city area respectively.

Dry land is widely distributed in all regions of the city. The paddy field occupies a relatively small area as a whole, mainly distributed near Nansi Lake. Woodland is mainly distributed in the mountainous and hilly areas in the eastern part of Jining City. The area of grass is larger than that of woodland and is similar to the main distribution area of woodland. The waters are concentrated in the Nansi Lake area. Town house is concentrated in central urban areas. House-site in the countryside is distributed in all regions with little difference. The unutilized land area is the smallest, mainly distributed in the rocky bare land in the north.

Table 2. Land use status in Jining City in 2015

\begin{tabular}{cccccccccc}
\hline & dry land & $\begin{array}{c}\text { paddy } \\
\text { field }\end{array}$ & woodland & grass & waters & $\begin{array}{c}\text { town } \\
\text { house }\end{array}$ & $\begin{array}{c}\text { House-site } \\
\text { in the } \\
\text { countryside }\end{array}$ & $\begin{array}{c}\text { unutilized } \\
\text { land }\end{array}$ & total \\
\hline $\begin{array}{c}\text { area } \\
\left(\mathrm{hm}^{2}\right)\end{array}$ & 651505.39 & 9223.06 & 26286.63 & 25015.70 & 135459.84 & 72147.26 & 186166.88 & 2889.95 & 1108694.71 \\
$\begin{array}{c}\text { structure } \\
(\%)\end{array}$ & 58.76 & 0.83 & 2.37 & 2.26 & 12.22 & 6.51 & 16.79 & 0.26 & 100 \\
\hline
\end{tabular}

\subsection{Land use characteristics and problems}

\subsubsection{Land use characteristics}

The characteristics of land use in Jining City are typical of developed agricultural areas. Based on the above analysis, the characteristics of land use in Jining City can be summarized as follows:

(1) High arable land rate

In the land use structure, the cultivated land of Jining City has an absolute advantage, accounting for $64.16 \%$ of the total land area.

(2) High land utilization rate

The land utilization rate can be expressed as the percentage of the used land in the total land area. The proportion of unutilized land in Jining City is only $0.34 \%$, and the land utilization rate is $99.66 \%$. It shows that the degree of land use in the study area is very high.

(3) The water area has a large proportion and the surface water resources are abundant

Jining City has a large water area, accounting for $11.43 \%$ of the city's area. It is the area with the largest water area in Shandong Province. Nansi Lake, the largest lake in Shandong Province, is located in Weishan County of Jining City. With the continuous increase of coal mining subsidence area, the water area of Jining City will gradually increase.

(4) Regional differences in land use are obvious

The spatial structure pattern of land use is as follows: In Jining City, cultivated land is the main land type, of which dry land is widely distributed throughout the region, while paddy field are mainly distributed near 
Nansi Lake. The construction land is concentrated and contiguous and scattered, among which house-site in the countryside is scattered throughout the district. The spatial distribution of waters, woodland and grass are obviously different, and the regional characteristics are strong. Most of the waters are concentrated in the southeast. In the hilly and mountainous areas of the east, the surface is rugged, and woodland and grass are mainly distributed here. However, with the impact of human activities and climate change, the problem of soil erosion will increasingly affect the ecological security of the region.

\subsubsection{Land use problems}

According to the analysis of land use structure and characteristics of land use, it can be seen that Jining City has some problems in the process of land use, mainly including:

(1) The land use structure is unreasonable.

Judging from the current land use structure, the area of cultivated land is the largest, and the proportion of woodland and grass is low; in construction land, the proportion of town house is relatively low, and housesite in the countryside is relatively large. Due to the greater man-made effects of cultivated land, and the obvious effect of woodland and grass in maintaining the ecological environment, this directly affects the ecological environment of the region; especially in the western plains, the ecosystem is single, mainly agricultural ecosystem, lacking forest ecology barrier. With the continuous expansion of town house, other land is constantly being squeezed, leading to increased vulnerability of land use. With the development of society and economy, deforestation and excessive reclamation have greatly reduced the vegetation coverage. The acceleration of urban construction and the rapid increase of various engineering projects have made the soil erosion in the plains increasingly worse, the quality of land has declined, and the ecological carrying capacity has declined.

(2) Per capita land resources are scarce, and the contradiction between people and land is increasingly prominent.

Jining City has vast land resources and superior natural conditions, but per capita land resources are small, especially agricultural land resources.

The rapid population growth and rapid economic development have promoted the increasing construction of urban construction, commercial enterprises, transportation and energy and other infrastructure construction, and the occupation of cultivated land has increased, and construction land has gradually replaced cultivated land, vegetable fields and other agricultural land. A large number of land use problems have been produced with it, such as changes in the regional natural environment, changes in the ecosystem, food security issues, and land use contradictions between industries, which affect the sustainable development of the socioeconomic environment to a certain extent.
The rapid population growth, rapid economic development and high degree of agriculturalization are the main reasons for the reduction of woodland. In order to better improve the regional ecological environment, the degree of greening should be increased accordingly in the future to prevent deforestation and ensure the effective amount of woodland.

\section{Land use area and structure change}

After calculation, the changes in land use area and structure of Jining City are as follows.

\subsection{Change in dry land}

During 2000-2015, the area of dry land showed a trend of first increasing and then decreasing, and the overall area increased slightly. The area of dry land increased from $691467.92 \mathrm{hm}^{2}$ in 2000 to $701140.44 \mathrm{hm}^{2}$ in 2015 , and its proportion increased from $62.37 \%$ to $63.24 \%$, and the total area increased by $9672.52 \mathrm{hm}^{2}$. Dryland changes show obvious phases. During 2000-2005, the dryland area increased by $45159.71 \mathrm{hm}^{2}$, the structure changed $4.07 \%$, and the change was large; during 2005-2010, the dryland area decreased by $16,108.47$ area, and the structure changed $1.45 \%$, which was more During the period 2010-2015, the area of dry land decreased by $19378.72 \mathrm{hm}^{2}$, the structure change was $1.75 \%$, and the change was small. This is closely related to the rapid economic development of Jining during this period. After 2000, with the economic development, population increase, and the acceleration of urbanization, the construction land for cities, industrial and mining, and residential areas developed rapidly, occupying a large amount of cultivated land.

\subsection{Change in paddy field}

From 2000 to 2015, the area of paddy field showed a trend of first decreasing, then increasing and then decreasing, and the overall area decreased. The area of paddy field has been reduced from $57647.11 \mathrm{hm}^{2}$ in 2000 to $10200.02 \mathrm{hm}^{2}$ in 2015 , the proportion of which has decreased from $5.20 \%$ to $0.92 \%$, and the total area has decreased by $47447.09 \mathrm{hm}^{2}$. During the period 2000-2005, the area of paddy field decreased by $48304.94 \mathrm{hm}^{2}$, and the structure changed by $4.36 \%$, which was a large change; during the period 2005-2010, the area of paddy fiel increased by $3,054.73 \mathrm{hm}^{2}$, with a structural change of $0.28 \%$, and the change was small. From the overall change in the area of dry land and paddy field, it can be seen that the area of arable land has decreased by $37774.57 \mathrm{hm}^{2}$.

\subsection{Change in woodland}

From 2000 to 2015, the area of woodland showed a trend of first increasing and then decreasing, and the overall area increased. The area of woodland increased from $23545.70 \mathrm{hm}^{2}$ in 2000 to $29269.62 \mathrm{hm}^{2}$ in 2015 , the proportion increased from $2.12 \%$ to $2.64 \%$, and the total 
area increased by $5723.92 \mathrm{hm}^{2}$. During the period 2000 2005 , the area of woodland increased by $5,123.28 \mathrm{hm}^{2}$, with a structural change of $0.47 \%$, and the change was large; during the period 2005-2010, the area of woodland increased by $1394.90 \mathrm{hm}^{2}$, with a structural change of $0.12 \%$, and the change was small; from 2010 to 2015 , the area of woodland reduced by $794.26 \mathrm{hm}^{2}$, the structure change was $0.07 \%$, the change was small.

\subsection{Change in grass}

From 2000 to 2015, the area of grass showed a continuous decrease. The grass area has been reduced by $9635 \mathrm{hm}^{2}$ and the structure has changed by $0.87 \%$.

\subsection{Change in water}

During the period 2000-2015, the water area showed a trend of first increasing and then decreasing, and the overall area increased. The water area increased from $125918.44 \mathrm{hm}^{2}$ in 2000 to $126724.15 \mathrm{hm}^{2}$ in 2015 , and its proportion increased from $11.36 \%$ to $11.43 \%$, and the overall area increased by $805.71 \mathrm{hm}^{2}$. During the period 2000-2005, the water area increased by $4556.77 \mathrm{hm}^{2}$, the structure changed $0.41 \%$, and the change was large; from 2005 to 2010 , the water area increased by $1145.96 \mathrm{hm}^{2}$, the structure change was $0.10 \%$, and the change was small; from 2010 to 2015 The water area has decreased by $4897.02 \mathrm{hm}^{2}$, and the structure has changed by $0.44 \%$, which is a big change.

\subsection{Change in town house}

During the period 2000-2015, the town house area showed the characteristics of continuous growth. The town house area increased by $26123.78 \mathrm{hm}^{2}$, and the structural change was $5.52 \%$. 4.7

\subsection{Change in house-site in the countryside}

From 2000 to 2015, the land area of house-site in the countryside showed a trend of first decreasing, then increasing and then decreasing, and the overall area decreased. The land area of house-site in the countryside decreased from $116847.75 \mathrm{hm}^{2}$ in 2000 to $97454.53 \mathrm{hm}^{2}$ in 2015 , and the proportion was reduced from $10.54 \%$ to $8.79 \%$, and the total area decreased by $19393.22 \mathrm{hm}^{2}$. During the period 2000-2005, the land area of house-site in the countryside decreased by $15925.28 \mathrm{hm}^{2}$, and the structural change was $1.44 \%$, which was a large change; during the period 2005-2010, the land area of house-site in the countryside increased by $1729.66 \mathrm{hm}^{2}$, with a structural change of $0.16 \%$, and the change was small; During 2015, the land area of house-site in the countryside decreased by $5197.6 \mathrm{hm}^{2}$, and the structural change was $0.47 \%$, which was relatively small. From the changes in the area of town house and house-site in the countryside, it can be seen that the total construction land area of town house and house-site in the countryside increased by $6,730.56 \mathrm{hm}^{2}$. This is closely related to rapid economic development, urban expansion, and population growth.

\subsection{Change in unutilized land}

During the period 2000-2015, the area of unutilized land showed a change characteristic of first decreasing and then increasing, and the overall area decreased. The area of unutilized land decreased from $4714.67 \mathrm{hm}^{2}$ in 2000 to $3,769.27 \mathrm{hm}^{2}$ in 2015 , and its proportion decreased from $0.43 \%$ to $0.34 \%$. The overall area was reduced by $945.4 \mathrm{hm}^{2}$ and the structural change was $0.09 \%$.

\section{Conclusion and prospect}

\subsection{Conclusion}

The current rapid social and economic development, rapid population growth, and acceleration of urbanization are all promoting changes in land use in Jining City, which in turn affects the overall environment of Jining City. As a typical inland city in Shandong Province, Jining City has complex and diverse landforms, developed water systems, and has the largest freshwater lake in Shandong Province-Nansi Lake. A good study of the land use changes in this area will be of great significance to the sustainable development and ecological protection of Jining City. Taking the four LANDSAT remote sensing images of 2000, 2005, 2010, and 2015 as the main data source, based on the preprocessing of the images, the land use classification system and interpretation signs of Jining City were formulated, and RS and GIS technology were applied. The human-computer interactive visual interpretation of the 4 phases of remote sensing images was performed, and the classification effect was good. The land use in Jining City was analyzed and the following conclusions were drawn:

(1) Jining City has the largest area of dry land, about $651505.39 \mathrm{hm} 2$, accounting for $58.76 \%$ of the total area of Jining City, which is widely distributed in all regions. The second is construction land, accounting for $23.3 \%$ of the city's total area, of which house-site in the countryside accounts for $16.79 \%$, and town house accounts for $6.51 \%$. The water area accounts for $12.22 \%$, concentrated in the Nansi Lake area. Grass, woodland, paddy field, and unutilized land are relatively small, accounting for $2.37 \%, 2.26 \%, 0.83 \%$, and $0.26 \%$ of the city area respectively. They are distributed in the mountainous and hilly areas of the eastern region, near Nansi Lake, and bare rocky land in the north.

(2) The land use characteristics of Jining City are: high arable land rate, high land utilization rate, large proportion of water area, abundant surface water resources, and obvious regional differences in land use; the problems are that the land use structure is unreasonable, per capita land resources are few, and the contradiction between people and land has become increasingly prominent.

(3) On the whole, the land use changes in Jining City are relatively complex. The town house area has been 
showing an increasing trend; the grass area has shown a continuous decreasing trend; the fluctuations of dry land, paddy field, woodland, house-site in the countryside, water, and unutilized land area fluctuations are obvious. The area of dry land showed a trend of first increasing and then decreasing, and the overall area increased slightly; the area of paddy field showed a trend of first decreasing, then increasing and then decreasing, and the overall area decreased; the area of woodland showed a trend of first increasing and then decreasing, and the overall area increased; The water shows a trend of first increasing and then decreasing, and the overall area has increased; the area of house-site in the countryside has shown a trend of first decreasing, then increasing and then decreasing, and the overall area has decreased; the unutilized land area has shown a change characteristic of first decreasing and then increasing, the overall area has been reduced. During the 15 years from 2000 to 2015, the largest change in the land use structure of Jining City was town house, with a structural change of $5.52 \%$; the others were paddy field, house-site in the countryside, dry land, grass, woodland, unutilized land, and water. The structural changes were respectively It is $4.28 \%$, $1.75 \%, 0.87 \%, 0.87 \%, 0.52 \%, 0.09 \%, 0.07 \%$. Among them, the area of town house, dry land, woodland, and water has increased, while the area of paddy field, housesite in the countryside, grass, and unutilized land has decreased. The largest change in land use area in Jining City is town house, which is $61220.93 \mathrm{hm}^{2}$, and the others are paddy field, house-site in the countryside, dry land, grass, woodland, unutilized land, and water, respectively, $47447.09 \mathrm{hm}^{2}, 19393.22 \mathrm{hm}^{2}, 9672.52 \mathrm{hm}^{2}, 9635 \mathrm{hm}^{2}$, $5723.92 \mathrm{hm}^{2}, 945.4 \mathrm{hm}^{2}, 805.71 \mathrm{hm}^{2}$.

\subsection{Prospect}

In the process of analyzing land use in Jining City, certain results have been achieved, but some problems and shortcomings have also been discovered.

The main data collected in this article comes from remote sensing images and related statistical data. Other data is lacking and requires more spatial data to assist research, such as soil texture, soil type, etc. With these, it will be possible to analyze land use more clearly; On the spatial scale, the research should be divided into smaller regional units; at the same time, the research only stays on the theory, and there is a lack of field investigation and research. If the field investigation can be carried out in depth, it will be more conducive to the significance of research. This paper mainly analyzes the existing situation, and lacks the prediction of the future situation. If a longer-term study is done in the future, it will help the practical application of the analysis, such as land use planning.

\section{References}

1. Skole DL, Chomentowski W, Salas WA. et al. (1994) Physical and human dimensions of deforestation in Amazonia. BioScience, 44:314322 .
2. Kienast F. (1993) Analysis of historic landscape patterns with a geofraphical information system-a methodological outline. Landscape ecology, 8:103118.

3. Iverson L, Prasad A. (1998) Estimating regional plant biodiversity with GIS modelling. Diversity and Distributions, 4:49-61.

4. Tang H, Wu W, Yang P, et al. (2009) Recent progresses of land use and land cover change (LUCC) models. Acta Geographica Sinica-Chinses Edition, 64: 456-468.

5. Li X (1999). Change of arable land area in China during the past 20 years and its policy implications. Journal of Natural Resources, 14: 329-333

6. Li, M, Zhang H. (2003). Provincial difference in cultivated land and grain productivity in China. Resources Science, 25: 49-56.

7. Shi P, Pan Y, CHEN J, et al. (1999) Land use/cover change and environmental security in Shenzhen region. Journal of Natural Resources, 14: 293-299

8. Li J, Ren Z. (2007). Research on the Value of Soil and Water Conservation in Loess Plateau in Northern Shaanxi Province. Scientia Agricultura Sinica, 40:2796-2803.

9. Liu J, Kuang W, Zhang Z, et al. (2014) Spatiotemporal characteristics, patterns, and causes of land-use changes in China since the late 1980s. Journal of Geographical Sciences, 24: 195-210.

10. Liu J, Ning J, Kuang W, et al. (2018) Spatiotemporal patterns and characteristics of land-use change in China during 2010-2015. Journal of Geographical Sciences, 28: 547-562. 